\title{
Management of sleep apnoea syndrome
}

\author{
G. Liistro*, G. Aubert**, D.O. Rodenstein*
}

\begin{abstract}
Management of sleep apnoea syndrome. G. Liistro, G. Aubert, D.O. Rodenstein. (CERS Journals Ltd 1995.

ABSTRACT: Obstructive sleep apnoea is a chronic condition characterized by repetitive episodes of upper airway collapse during sleep, leading to sleep fragmentation. The management of sleep apnoea consists of general and specific measures.

General measures should include weight loss in overweight patients; avoidance of alcohol during the evening hours; avoidance of any hypnotic drug. Specific measures may range from simple position training in patients with positional sleep apnoea (sleep apnoea appearing only when lying on the back) of slight severity; to oral appliances with the aim of creating a prognathism during sleep, to the introduction of a nasopharyngeal tube during sleep every night. When position training, oral appliances or a nasopharyngeal tube are used, their effect should be monitored by full night polysomnography.

The best specific treatment for sleep apnoea is nasal continuous positive airway pressure. The main problem with nasal continuous positive airway pressure is the long-term compliance which should be assessed regularly over the years. In cases where nasal continuous positive airway pressure is not tolerated or compliance is bad, a surgical treatment can be proposed. Uvulopalatopharyngoplasty seems to give disappointing results. By contrast, maxillomandibular surgery is credited with the best results available as far as surgery is concerned, comparable to nasal continuous positive airway pressure.

Eur Respir J., 1995, 8, 1751-1755.
\end{abstract}

The management of patients with sleep apnoea should aim to achieve three objectives: 1) alleviation of symptoms; 2) decrease in morbidity; and 3) decrease in mortality.

As in many diseases, when several options exist, the choice of a particular treatment for a particular patient should take into account the effect of the treatment on these three objectives. In addition, the side-effects of therapy should be considered, and the treatment with the lowest possible level of side-effects should have a high priority.

In the majority of diseases, the development of medical treatments has been empirical and based on symptom alleviation. Sleep apnoea, essentially the obstructive type, is an exception to this rule. Indeed, therapy of sleep apnoea was from the beginning based on the pathophysiology of the disease [1]. Since obstructive sleep apnoea is due to a complete or incomplete collapse of the upper airway at the pharyngeal level during sleep, treatments have been designed to circumvent the obstruction or to prevent it. The effects of treatments upon morbidity and mortality have only recently come under scrutiny and criticism [2]. Data are still scarce for objectively assessing some of these effects [3, 4]. In 1995, it is thus difficult, and perhaps more difficult than 10 yrs ago, to obtain a clear picture of the optimal management of patients with sleep apnoea.
*Pneumology and **EEG Units, Cliniques Universitaires Saint Luc, Université Catholique de Louvain, Brussels, Belgium.

Correspondence: D.O. Rodenstein Service de Pneumologie Cliniques Saint Luc Av. Hippocrate 10 1200 Brussels

Belgium

\section{Keywords: Management} sleep apnoea syndrome treatment

Received: February 131995

Accepted for publication February 151995
Weight loss

About three quarters of patients with obstructive sleep apnoea are obese [5]. There is a clear relationship between excess weight, usually expressed as the body mass index (BMI), and the number of sleep-related respiratory disturbances [6]. Some authors have found that the relationship is linked to the BMI, whereas others have suggested that the relationship is due to fat deposits in the neck, assessed through neck circumference [6]. In any case, weight loss has definite effects and results in improvement or (exceptionally) disappearance of sleeprelated disordered breathing in many patients [7]. The effect of weight loss may be due to an improvement in nasopharyngeal collapsibility or to an increase in lung volumes, oxygen reserve and an improvement in resting blood gases.

Weight loss is difficult to achieve and especially to maintain. Several studies have reported on weight loss obtained with caloric restriction in severely obese patients. In general, only modest reductions in BMI are obtained, with improvements in sleep architecture and sleep-related disordered breathing. However, cure of sleep apnoea is the exception rather than the rule [8]. 
Despite these disappointing results, weight loss should be encouraged in obese patients with obstructive sleep apnoea.

Several studies have reported on surgical procedures aimed at obtaining a substantial decrease in BMI. Most of them show significant improvements or cure of obstructive sleep apnoea in a limited number of patients $[9,10]$. Jejuno-ileal shunt, gastroplasty or gastric bypass have all been advocated. However, all these procedures carry a substantial risk of postoperative morbidity and mortality, and require strong and continuous motivation from patients [8].

\section{Alcohol and hypnotics avoidance}

There is a well-proven influence of a number of drugs on pharyngeal collapsibility. These include alcohol, hypnotics, sedatives, and opioid analgesics [11-13]. Experimental data exist in animals and humans showing that these drugs decrease the electromyographic (EMG) activity of pharyngeal muscles without interfering with the EMG activity of the diaphragm. Therefore, the balance between the dilating and collapsing forces at the pharyngeal level is altered with a resulting increase in collapsibility.

Alcohol and hypnotics do not cause obstructive sleep apnoea, but rather exaggerate it. Thus, their avoidance might seem a minor point. Nevertheless, one cannot forget that the extremely wide use both of alcohol and hypnotics makes this minor point quite important in the management of patients with obstructive sleep apnoea. Every effort must be made to decrease consumption of hypnotics and alcohol.

\section{Position training}

It is generally accepted that snoring increases in intensity when patients lie on their back, rather than on the side or on the belly. Several studies have shown that obstructive apnoeas are more frequent when the patients lie on their back $[14,15]$. Some authors have described groups of patients that only have obstructive apnoeas when lying on their back [16]. This is called positional obstructive sleep apnoea and, in this category of patients, it has been suggested that position training (training the patients to avoid sleeping on their back) could be enough to achieve the disappearance of obstructive sleep apnoea.

Exclusive positional sleep apnoea is probably present in a minority of patients. Position training may, nevertheless, be helpful in a large number of patients that have more apnoeas in the dorsal decubitus than in other positions. Position training may also be useful in patients having a low number of apnoeas, for instance 5-15 episodes $\cdot \mathrm{h}^{-1}$ who would not be considered for treatment by other means.

Position training may be obtained by a number of devices acting through acoustic signals, electric shocks, or discomfort. One simple method to avoid dorsal decubitus is to sew a pocket on the back of the pyjamas and to put inside a golf ball or a tennis ball.

\section{Oral appliances}

Oral appliances are prosthetic devices that either pull the tongue or the mandible forwards creating a prognathism. Oral appliances are used during the night, for sleeping. One group with a great deal of experience using this type of treatment has described improvements and even complete resolution of obstructive sleep apnoea, but results are less impressive in other studies [17-19].

Oral appliances, especially those designed for mandible advancement, have side-effects, such as excessive salivation or temporomandibular arthritis, that may be a reason for treatment failure. Overall compliance has been estimated at about $50 \%$. This treatment has been proposed as an alternative for patients unable to tolerate other types of treatment, such as nasal continuous positive airway pressure (nCPAP).

\section{Nasopharyngeal tube}

A few case reports and one short series have described the use of the nasopharyngeal tube to treat obstructive sleep apnoea $[20,21]$. The idea is that a small bore latex tube, 3-7 mm external diameter, is passed through the nose by the patient himself every night. The tube is about $15 \mathrm{~cm}$ length, so that the tip of the tube rests a couple of centimetres above the epiglottis. It is believed that the tube acts as an irritant, or as a mechanical device keeping the tongue away from the posterior pharyngeal wall. Other authors believe that people can breathe through the tube. This is unlikely, given its small internal diameter.

Few subjects are able to tolerate the nasopharyngeal tube for the whole night. The introduction of the tube is facilitated by lidocaine jelly. Even in subjects able to tolerate the tube, the results may vary. In a few subjects, obstructive sleep apnoea completely disappears. Success seems limited to mild forms of sleep apnoea in slim patients. More frequently, apnoeas are converted into hypopnoeas and sleep architecture is not significantly modified [18].

The main advantages of this method are its low cost and simplicity. Patients can use it as an alternative to other forms of treatment, such as nasal continuous positive airway pressure, for instance during short trips away from home.

\section{Surgical management of obstructive sleep apnoea}

Surgical management of obstructive sleep apnoea includes several different techniques. We shall briefly review those most frequently used: tracheostomy, tonsillectomy and nasal surgery, uvulopalatopharyngoplasty (UPPP) and its variants, and finally maxillomandibular osteotomy.

Tracheostomy, almost completely abandoned today, 
was the first treatment described in obstructive sleep apnoea $[1,2,22]$. Tracheostomy acts by allowing airflow to take place below the pharyngeal obstruction [1]. Indeed, the airway outlet with a tracheostomy is located below the pharyngeal obstruction. The effects of tracheostomy are immediate, with complete normalization of breathing and sleep architecture and fragmentation from the first night. The tracheostomy is closed during the daytime, to allow normal nasal breathing and speech, and is opened at night.

The well-known side-effects of tracheostomy, including bleeding, excessive secretions and coughing, granuloma formation and infection, led to its substitution by less aggressive alternatives when these became available.

Tonsillectomy and nasal surgery may be extremely useful in children, in whom this type of surgery can cure obstructive sleep apnoea [23]. This is not the case in adults, where encouraging results from early studies have been unconfirmed in later ones [24]. Nevertheless, nasal surgery may still be needed in the implementation of nCPAP (see below) in patients in whom this type of therapy fails due to nasal blocking or nasal obstruction for structural reasons.

UPPP consists in a wedge resection of the posterior pillar mucosa adjacent to the root of the uvula, with removal of the pillar mucosa between the palatal arches. Many variations of the technique exist, including section and removal of the entire uvula, removal of some muscle (the more dorsal part of the levator, and part of the palatoglossus and/or palatopharyngeus), tonsillectomy, and resection of part of the base of the tongue [25].

When surgical success is defined as a reduction of $50 \%$ or more in the respiratory disturbance index, most show a success rate of about $50 \%$. However, not all data agree. Many series show success (defined as 50\% reduction of sleep-related disordered breathing) in less than half of the patients. If success is defined as a normalization of sleep structure and fragmentation and less than 10 respiratory disturbance events per hour of sleep, the success rate of UPPP is less than $50 \%$, but is very difficult to evaluate in quantitative terms in the literature. Indeed, most series do not report enough data to verify the effects of surgery on sleep [26].

UPPP-related morbidity is characterized by pain, rhinolalia and transient nasopharyngeal reflux. Haemorrhage is not infrequent and can be life-threatening. In one published series, mortality due to UPPP was about $1 \%$ [27].

It is, up to now, quite difficult to predict which patients are more likely to benefit from UPPP. Many different methods have been applied in attempting to predict the more likely anatomical level of obstruction in the pharynx. These include endoscopy during wakefulness, cephalometrics, computed tomography (CT)-scan and magnetic resonance of the pharynx, multiple pressure catheter monitoring during sleep, cineradiography, acoustic reflection, and more recently pharyngeal endoscopy during sleep with the pharynx in a completely passive configuration [28]. None of the above techniques seem able to predict the patients who will benefit from UPPP and those who will not [29].
Some data exist on mortality after UPPP compared to "spontaneous" mortality (i.e. mortality when therapy was limited to advice on weight loss). One published series showed that after UPPP mortality was the same as without treatment and amounted to as much as $40 \%$ at 9 yrs [2]. A recent paper concluded that mortality was the same after UPPP as with treatment by nCPAP [30]. However, on close scrutiny, cardiovascular mortality (i.e. mortality presumably due to the obstructive sleep apnoea) appears significantly higher after UPPP.

Maxillomandibular surgery is credited with the best results available as far as surgical therapy of obstructive sleep apnoea is concerned (i.e. comparable to nCPAP or tracheostomy). This type of surgery consists of a variable combination of several surgical procedures performed sequentially and including anterior mandibular osteotomy, hyoid bone suspension, Lefort I osteotomy, sagittal splitting of the mandibular ramus. The whole procedure may take 6-8 months, and patients should remain under nCPAP during this period. This approach is technically demanding, and only a small number of groups have reported on a substantial number of patients. The results are as good as with nCPAP, and lead to normalization both of breathing and sleep abnormalities [31].

\section{Nasal continuous positive airway pressure}

This therapeutic method involves connecting the subject to a blower delivering air at a predetermined positive pressure, that is continuously maintained throughout both phases of the respiratory cycle [32]. The connection is generally performed via the nose, with a variety of nasal masks. The positive pressure acts as a pneumatic splint opening up the occluded pharyngeal airway, and allowing the patient to breathe. The level of pressure required $\left(5-15 \mathrm{cmH}_{2} \mathrm{O}\right.$ in most patients) must be individually determined, and must be high enough to eliminate snoring, hypopnoeas, apnoeas and sleep fragmentation. A large variety of commercial nCPAP devices are now available on the market, with an extensive number of mask models for all sizes and forms of nose.

Nasal CPAP has side-effects: skin sores and erosions, nasal stuffiness, blocking or congestion, and discomfort due to the device itself (essentially noise and bulkiness) [33]. The beneficial effects of nCPAP are rapid and spectacular, with almost complete disappearance of sleepiness and nocturia from the first night of therapy [34].

Although some cases of cure after relatively short periods of nCPAP have been published, the general rule is that treatment must be applied every night for an undetermined period of time (perhaps lifelong). This poses the problem of compliance to long-term therapy. Several recent papers have reported on very poor short- and medium-term compliance to nCPAP, much less than previously believed [35]. However, unpublished data show that good levels of compliance can be obtained. In 84 patients on nCPAP we found, over a 2 year follow-up period, a median daily use of nearly $6 \mathrm{~h}$, with $77 \%$ of 
patients exceeding $4 \mathrm{~h}$ of use per night. For 34 patients with two consecutive follow-up periods (about 1 and 2 yrs respectively), there was no significant difference in compliance between the two periods. It may be postulated that the implementation of nCPAP constitutes a critical period that may influence compliance to therapy, insofar as enough time is dedicated to the patient to explain the benefits and limitations of the treatment, its side-effects and the means to solve them.

In patients needing high levels of pressure, some authors have proposed the use of devices with two levels of pressure: a higher one limited to the inspiratory time and a lower one during expiration. On randomized studies however, the use of these more sophisticated (and expensive) machines does not seem to bring any advantage with respect to nCPAP [36].

In conclusion, obstructive sleep apnoea is a symptomatic disease associated with morbidity and mortality. Treatments exist that allow symptom disappearance and reduce mortality. General measures including alcohol and hypnotics avoidance and weight loss should be strongly and continuously recommended. For patients (and doctors) looking for a radical cure, a surgical option does exist, i.e. maxillofacial surgery. However, it should be remembered that this is not a single operation, but rather a series of procedures extending over several months during which patients should receive nCPAP, until polysomnographic controls demonstrate the disappearance of sleep apnoea [37]. Surgical risk is of concern, as is the technical expertise of the surgical team. Uvulopalatopharyngoplasty (and its numerous variations) should not be considered as an established therapy for sleep apnoea; it does not seem to decrease mortality in the long-term and results cannot be reliably predicted before the operation.

Nasal continuous positive airway pressure is the best medical treatment available. It is effective, quite rapid in action and generally well-accepted. However, it is a lifelong therapy, with a number of not serious but disturbing side-effects that must be adequately managed by an experienced, receptive and available team.

Position training, oral appliance and the nasopharyngeal tube may be useful in selected patients, or as an adjunct for short interruptions of nCPAP therapy.

Pharmacological treatments are not available at present. Given the large number of potential patients that recent epidemiological studies have brought to light [38], full control of obstructive sleep apnoea will be a difficult task until drugs become available.

\section{References}

1. Kulho W, Doll E, Franck MC. Erfolgreiche Behandlung eines Pickwick-Syndromes durch eine Dauertracheal Kanule. Dtsch Med Wschr 1969; 94: 1286-1290.

2. He J, Kryger MH, Zorick FJ, Conway W, Roth T. Mortality and apnea index in obstructive sleep apnea: experience in 385 male patients. Chest 1988; 94: 9-14.

3. Grunstein RR. Sleep apnoea - evolution and doubt. Eur Respir J 1994; 7: 1741-1743.
4. Sforza E, Addati G, Cirignotta F, Lugaresi E. Natural evolution of sleep apnoea syndrome: a five year longitudinal study. Eur Respir J 1994; 7: 1765-1770.

5. Guilleminault C, Tilkian A, Dement W. The sleep apnea syndromes. Ann Rev Med 1976; 27: 465-484.

6. Stradling JR, Crosby JH. Predictors and prevalence of obstructive sleep apnoea and snoring in 1,001 middleaged men. Thorax 1991; 46: 85-90.

7. Suratt PM, McTier R, Findley LJ, Pohl SL, Wilhoit SC. Changes in breathing and the pharynx after weight loss in obstructive sleep apnea. Chest 1987; 92: 631-637.

8. Aubert G. Alternative therapeutic approaches in sleep apnea syndrome. Sleep 1992; 15: S69-S72.

9. Harman AM, Wynne JW, Block AJ. The effect of weight loss on sleep-disordered breathing and oxygen desaturation in morbidity obese men. Chest 1982; 82: 291294.

10. Peiser J, Lavie P, Ovnat A, Charuzi I. Sleep apnea syndrome in the morbidity obese as an indication for weight reduction surgery. Ann Surg 1984; 199: 112-115.

11. Bonora M, St John WM, Bledsoe TA. Differential elevation by protriptyline and depression by diazepam of upper airway respiratory motor activity. Am Rev Respir Dis 1985; 131: 41-45.

12. Hwang JC, St John WM, Bartlett D. Respiratoryrelated hypoglossal nerve activity: influence of anesthetics. J Appl Physiol: Respirat Environ Exercise Physiol 1983; 55: 785-792.

13. Robinson RW, Zwillich CW. The effects of drugs on breathing during sleep. Clin Chest Med 1985; 6: 603-614.

14. Lerner SA, Cecil WT. The effect of sleeping posture on obstructive sleep apnea (Abstract). Chest 1984; 86: 327.

15. McEvoy RD, Sharp DJ, Thornton AT. The effects of posture on obstructive sleep apnea. Am Rev Respir Dis 1986; 133: 662-666.

16. Cartwright RD, Diaz F, Lloyd S. The effects of sleep posture and sleep stage on apnea frequency. Sleep 1991; 14: 351-353.

17. Cartwright RD, Samelson CF. The effects of a nonsurgical treatment for obstructive sleep apnea: the tongueretaining device. J Am Med Assoc 1982; 248: 705-709.

18. Schmidt-Nowara WW, Meade TE, Hays MB. Treatment of snoring and obstructive sleep apnea with a dental orthosis. Chest 1991; 99: 1378-1385.

19. Eaton E, Atkins M, Schaar Y, Stone P, Thompson R, Woodcock A. Orthodontic device vs CPAP for sleep apnoea syndrome: effect on paradoxical breathing, apnoea and sleep disturbance (Abstract). Am J Respir Crit Care Med 1994; 149: A496.

20. Afzelius LE, Elmqvist D, Hougaard K, Laurin S, Nilson B, Risberg AM. Sleep apnea syndrome: an alternative treatment to tracheostomy. Laryngoscope 1981; 91: 285-291.

21. Nahmias JS, Karetzky MS. Treatment of obstructive sleep apnea syndrome using a nasopharyngeal tube. Chesr 1988; 94: 1142-1147.

22. Partinen M, Guilleminault C. Daytime sleepiness and vascular morbidity at seven year follow-up in obstructive sleep apnea patients. Chest 1990; 97: 27-32.

23. Eliaschar I, Lavie P, Halperin E, Gordon C, Alroy G. Sleep apneic episodes as indications for adenotonsillectomy. Arch Otolaryngol Head Neck Surg 1980; 106: 492-496.

24. Aubert-Tulkens G, Hamoir M, Van den Eeckhaut J, Rodenstein DO. Failure of tonsil and nose surgery in adults with longstanding severe sleep apnea syndrome. Arch Intern Med 1989; 149; 2118-2121. 
25. Fujita S, Conway W, Zorick F, Roth T. Surgical correction of anatomic abnormalities in obstructive sleep apnea syndrome: uvulopalatopharyngoplasty. Otolaryngol Head Neck Surg 1981; 89: 923-934.

26. Rodenstein DO. Assessment of uvulopalatopharyngoplasty for the treatment of sleep apnea syndrome. Sleep 1992; 15: S56-S62.

27. Harmon JD, Morgan W, Chaudhary B. Sleep apnea: morbidity and mortality of surgical treatment. South Med $J$ 1989; 82: 161-164.

28. Launois SH, Feroah TR, Campbell WN, et al. Site of pharyngeal narrowing predicts outcome of surgery for obstructive sleep apnea. Am Rev Respir Dis 1993; 147: 182-189.

29. Collard P, Aubert G, Rodenstein DO. Site of pharyngeal narrowing predicts outcome of surgery for OSA (Letter to the Editor). Am Rev Respir Dis 1993; 148: 819-820.

30. Keenan SP, Burt H, Ryan F, Fleetham IA. Long-term survival of patients with obstructive sleep apnea treated by uvulopalatopharyngoplasty or nasal CPAP. Chest 1994; 105: 155-159.

31. Riley RW, Powell NB, Guilleminault C. Obstructive sleep apnea syndrome: a review of 306 consecutively treated surgical patients. Otolaryngol Head Neck Surg 1993; 108: 117-125.
32. Sullivan CE, Berthon-Jones M, Issa M, Eves L. Reversal of obstructive sleep apnea by continuous positive airway pressure applied through the nose. Lancet 1981; 1: 862-865.

33. Hoffstein V, Mateika S, Conway J. Treatment of obstructive sleep apnea with nasal continuous positive airway pressure. Am Rev Respir Dis 1992; 145: 841-845.

34. Polo O, Berthon-Jones M, Douglas NJ, Sullivan CE. Management of obstructive sleep apnoea/hypopnoea syndrome. Lancet 1994; 344: 656-660.

35. Engleman HM, Martin SE, Deary IJ, Douglas NJ. Effect of continuous positive airway pressure treatment on daytime function in sleep apnoea/hypopnoea syndrome. Lancet 1994; 343: 572-575.

36. Reeves-Hoché MK, Hudgel DW, Meck R, Witteman R, Ross A, Zwillich CW. Continuous versus bilevel positive airway pressure for obstructive sleep apnea. Am J Respir Crit Care Med 1995; 151: 443-449.

37. Rennotte MT, Baele P, Aubert G, Rodenstein DO. Nasal continuous positive airway pressure in the perioperative management of patients with obstructive sleep apnea submitted to surgery. Chest 1995; 107: 367-374.

38. Young T, Palta M, Dempsey J, Skatrud J, Weber S, Badr S. The occurrence of sleep-disordered breathing among middle-aged adults. N Engl J Med 1993; 328: 12301235 . 